University of Nebraska - Lincoln

DigitalCommons@University of Nebraska - Lincoln

Modelling female mating success during mass trapping and natural competitive attraction of searching males or females

John A. Byers

USDA-ARS, john.byers@ars.usda.gov

Follow this and additional works at: https://digitalcommons.unl.edu/usdaarsfacpub

Byers, John A., "Modelling female mating success during mass trapping and natural competitive attraction of searching males or females" (2012). Publications from USDA-ARS / UNL Faculty. 1095. https://digitalcommons.unl.edu/usdaarsfacpub/1095

This Article is brought to you for free and open access by the U.S. Department of Agriculture: Agricultural Research Service, Lincoln, Nebraska at DigitalCommons@University of Nebraska - Lincoln. It has been accepted for inclusion in Publications from USDA-ARS / UNL Faculty by an authorized administrator of DigitalCommons@University of Nebraska - Lincoln. 


\title{
Modelling female mating success during mass trapping and natural competitive attraction of searching males or females
}

\author{
John A. Byers* \\ US Arid-Land Agricultural Research Center, USDA-ARS, 21881 North Cardon Lane, Maricopa, AZ 85138, USA \\ Accepted: 3 September 2012
}

Key words: computer simulation, monitoring, mating disruption, integrated pest management, IPM, mating systems, semiochemicals, effective attraction radius

\begin{abstract}
Simulation models of insects encountering sex pheromone with or without mass trapping in which the searching sex is either male (moths and many insect species) or female (some true bugs, beetles, and flies) were developed. The searching sex moved as a correlated random walk, while the opposite sex remained stationary (calling) and released an attractive sex pheromone. The searching sex was caught when encountering a pheromone-baited trap, and females mated when encountering a male. An encounter with pheromone was defined by the searcher's interception of a circle termed the effective attraction radius $\left(\mathrm{EAR}_{\mathrm{c}}\right)$. Parameters of movement (speed and duration), initial numbers of calling sex and searching sex, number of traps, area, and $\mathrm{EAR}_{\mathrm{c}}$ of traps and calling sex were varied individually to evaluate effects on the percentage of females mating. In the natural condition without traps, female mating success in both models was identical. Increasing the $\mathrm{EAR}_{\mathrm{c}}$ of the calling sex caused diminishing increases in female mating success, suggesting that evolution of larger pheromone release and $\mathrm{EAR}_{\mathrm{c}}$ is limited by increasing costs (production/sensitivity) relative to diminishing increases and benefits of mating encounters. With mass trapping, increasing the $\mathrm{EAR}_{\mathrm{c}}$ of traps or density of traps caused similar declines in female mating in both models, but the female-searching model predicted slightly lower mating success than the male-searching model. Increasing the $\mathrm{EAR}_{\mathrm{c}}$ of calling insects or the initial density of insects caused similar increases in female mating in both models, but again the female-searching model had slightly lower mating success than the malesearching model. The models have implications for mating lek formation and for understanding the variables affecting the success of mass trapping programs for insect pests with either male or female sex pheromones.
\end{abstract}

\section{Introduction}

Pheromones with attractive properties appear to be ubiquitous in insect mating systems. These pheromones can be characterized in regard to their attraction distances and the responding and producing sexes. Furthermore, attractive pheromones may be characterized by whether they act only on the opposite sex (sex pheromone), or act on both sexes (aggregation pheromone); there is a continuum between sex and aggregation pheromones. Pheromones are also characterized by which sex produces the pheromone. Usually, only one gender in a species produces the

*Correspondence: E-mail: john.byers@ars.usda.gov attractive pheromone (www.pherobase.net). Long-range sex pheromones in practically all moth species (Lepidoptera) have been shown to be produced only by the female and to attract only the male (Byers, 2006). Many other species across various insect orders (cockroaches, aphids, mealybugs, bugs, beetles, and flies) have female-produced sex pheromones to which males (male-searching model) are the only sex responding (www.pherobase.net).

In contrast to the male-searching model, there are more than a few species where males produce a sex pheromone that only attracts (or nearly so) females, which can be described as a female-searching model. For example, the male dried bean beetle, Acanthoscelides obtectus (Say) produces a sex pheromone attractive to females (Halstead, 1973), as do male desert beetles Parastizopus armaticeps 
(Péringuey) (Geiselhardt et al., 2008). Several cockroach species (Dictyoptera) have males that release sex pheromone to which only females respond (Sreng, 1990; Farine et al., 1994, 2007). At least one longhorn male beetle, the coffee white stemborer, Xylotrechus quadripes Chevrolat, produces a sex pheromone attracting females (Hall et al., 2006). Also, some stink bug species (Pentatomidae) have been discovered where males produce a sex pheromone that appears only to cause females to respond (Brézot et al., 1994; McBrien et al., 2001, 2002; Borges et al., 2007).

Leks (mating swarms) are invariably formed by males that produce an aggregation pheromone and 'call' for females, which join briefly to mate and then leave. Leks appear common in Hymenoptera and Diptera, for example, males of wood wasps (Cooperband et al., 2012) and many species of flies (Hoglund \& Alatalo, 1995; Field et al., 2002; Wicker-Thomas, 2007). Many important fruit fly pests (Tephritidae) as well as human disease-vectoring sand flies (Psychodidae) have male-produced sex pheromones that attract conspecific females (Jacobson et al., 1973; Chuman et al., 1987; Robacker, 1988; Hamilton et al., 1996; Khoo et al., 2000). However, in many cases the males can call singly as well as form lek mating swarms (Jarvis \& Rutledge, 1992; Shelly, 2001; Field et al., 2002; Quilici et al., 2002; Segura et al., 2007; Robacker et al., 2009). Thus, in many important pest species the males produce the sex pheromone that is attractive only to females, and some of these species may also form leks.

Mass trapping commonly uses many traps with pheromone dispensers in an area to attract one or both sexes and remove them before females mate and lay viable eggs (Shorey, 1977; El-Sayed et al., 2006, 2009; Byers, 2007, 2008). A similar method is mating disruption, which uses only dispensers that waste the time of one or both sexes orienting in pheromone plumes and/or become disoriented so mating occurrences are greatly reduced (Shorey, 1977; Cardé, 1990; Cardé \& Minks, 1995; Miller et al., 2006a,b). In these control methods, competitive attraction occurs when natural sources of pheromone from calling insects compete with sources of synthetic pheromone or semiochemicals from lures (Miller et al., 2006a,b). Byers (2007) used the 'effective attraction radius' (EAR) to represent the catching power of natural pheromone as well as an attractive trap's dispenser (competitive attraction) in models of mass trapping. The EAR of a pheromone source is defined as a theoretical sphere that would intercept the same number of insects as that caught by a trap releasing the pheromone. A specific EAR in meters for a particular species and pheromone release rate is calculated from the trap catch and the silhouette area of the trap compared to the catch on an unattractive (blank control) trap that catches at least one individual (Figure 1; Byers et al., 1989;

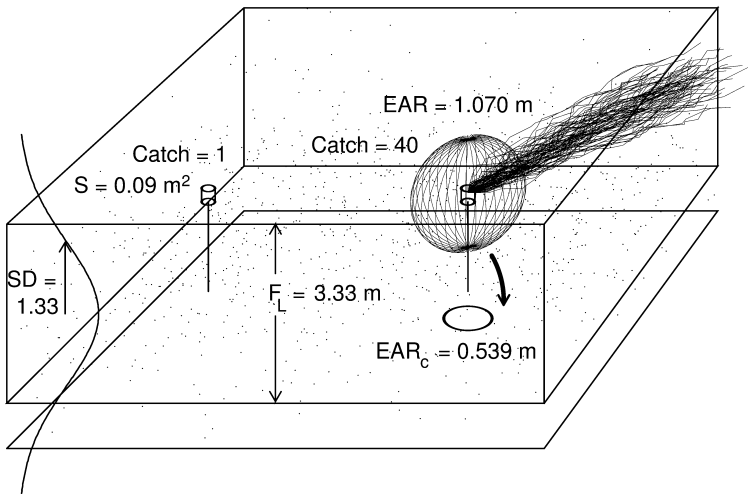

Figure 1 Two cylindrical sticky traps, a blank catching one insect $(\mathrm{Cb}=1)$ and a pheromone trap catching 40 insects $(\mathrm{Ca}=40)$, are each $0.09 \mathrm{~m}^{2}$ in silhouette area (S), giving a spherical $\mathrm{EAR}=[(\mathrm{Ca} \cdot \mathrm{S}) /(\pi \cdot \mathrm{Cb})]^{0.5}=1.070 \mathrm{~m}$ that can be converted to a circular $\mathrm{EAR}_{\mathrm{c}}=\pi \cdot \mathrm{EAR}^{2} /\left(2 \cdot \mathrm{F}_{\mathrm{L}}\right)=0.539 \mathrm{~m}$ (where $\mathrm{F}_{\mathrm{L}}=\mathrm{SD} \cdot \sqrt{2 \cdot \pi}=3.33 \mathrm{~m}$ ) (Byers, 2008). The black wavy lines represent a pheromone plume, whereas the small dots represent 1000 insects distributed vertically in a normal distribution $(\mathrm{SD}=1.33 \mathrm{~m})$.

Byers, 2008, 2009). An EAR indicates the strength of a pheromone source and depends on the chemical blend, release rate, and ecological function (e.g., short- or longrange) with regard to a species. In addition, multiple EAR conveniently represent pheromone sources in models instead of attempting to simulate complex spatial-temporal dimensions of attractive odor plumes interacting with insect orientation behaviors in the field (Figure 1).

The spherical three-dimensional EAR, measured from catches in the field, needs to be transformed into a circular EAR (termed $\mathrm{EAR}_{\mathrm{c}}$ ) for use in two-dimensional encounter-rate simulations of competitive attraction and camouflage (Byers, 2008). The conversion equation requires an estimation of the standard deviation (SD) of the vertical flight distribution (Byers, 2011) to obtain an effective flight layer, $\mathrm{F}_{\mathrm{L}}$ (Figure 1). Thus, the $\mathrm{EAR}_{\mathrm{c}}$ can be estimated from the vertical catch data of the species of interest and from the catch on the synthetic sex pheromone and blank traps such that models of mass trapping can be made predictive. The simulations also require estimates of average distance searched (or average flight speed and time of flight) that can be estimated from flight mill tests (e.g., $23 \mathrm{~km}$ for male pink bollworm moths; Wu et al., 2006). Densities of the searching and the calling sex can be measured in the field using EAR-related methods (Byers, 2012) along with determinations of $\mathrm{EAR}_{c}$ of calling sex and pheromone-baited traps. These predetermined values (or values varied) can then be used in simulations to explore the effect of different numbers of traps on female mating success. 
The first objective of this study was to explore differences in mating encounters, if any, between male- and female-searching systems when no pheromone traps were present. This would occur in natural environments or before mass trapping and mating disruption attempts of the last 40 years. The second objective was to compare the male-searching system of moths and many other insects as modelled earlier (Byers, 2007) with a new model of search by females when numerous pheromone-baited traps were employed. General assumptions of the models are that (1) the sex ratio is 1:1 as in most species, and (2) females mate only once, whereas moving or stationary males can mate repeatedly during the simulated period. In both the maleand the female-searching models, the searching sex can be caught by pheromone traps, but only the female (stationary or moving) is removed after mating (to begin egg laying). Implications for lek mating systems, such as female-searching with fewer sources of male-produced pheromone, will also be considered.

\section{Materials and methods}

A simulation model was constructed for females searching for stationary males competing with each other and sometimes with pheromone-baited traps to compare this to a previous model of male-searching moths (Byers, 2007). The new model had males represented by $\mathrm{EAR}_{c}$ of specified radius, remaining stationary, whereas females moved at specified speeds and durations (distances) within a rectangular area (female-searching model). The alternative model reversed the role of the sexes in producing and orienting to pheromone. In both models, males were never removed after mating encounters with females, whereas females were removed. Simulations proceeded until either the searching male or female had (1) taken the number of steps of constant length (depending on speed in $\mathrm{m} \mathrm{s}^{-1}$ ) required for the specified duration, or (2) all the searching sex were caught by traps, or (3) all the females were mated (Figure 2). Various numbers of searching females or males were placed at random within a rectangular area of specified xa and ya axes [e.g., in Java: Math.random ()$^{*}$ xa] to obtain specific initial densities. Pheromone traps, also represented by a specified $\mathrm{EAR}_{\mathrm{c}}$ (usually $2 \mathrm{~m}$ ) were usually placed at random, but with all centers spaced apart at least a minimum allowed distance (MAD) that was half the maximal spacing for a hexagonal pattern, $\mathrm{MAD}=0.5 \cdot(1.0746 / \sqrt{\mathrm{n} \cdot \mathrm{xa} \cdot \mathrm{ya}})$, where $\mathrm{n}$ is the number of traps. For high-density trap placements, the traps were placed at random, but with no overlap of EAR . $_{\text {. }}$

Individuals of the searching sex were initially placed at random points and usually moved a step (s) of $1 \mathrm{~m}$ each second in a correlated random walk. After initial directions

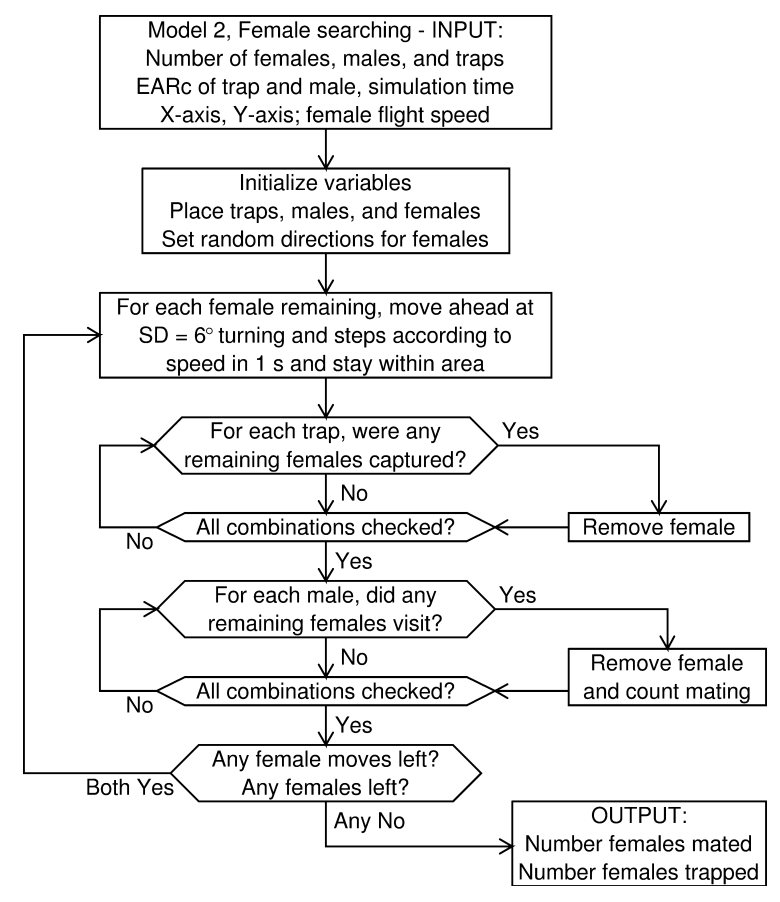

Figure 2 Flow diagram of simulation model 2 for femalesearching insects (see Figure 1 in Byers, 2007, for flow diagram of model 1, male-searching moths).

( $\alpha$ in radians) were chosen at random for each individual, each took steps between successive coordinates (e.g., $\mathrm{x}_{1}, \mathrm{y}_{1}$ to $\mathrm{x}_{2}, \mathrm{y}_{2}$ ) based on polar coordinates $\left[\mathrm{x}_{2}=\mathrm{x}_{1}+\right.$ $\left.s \cdot \cos (\alpha+\phi), y_{2}=y_{1}+s \cdot \sin (\alpha+\phi)\right]$ that deviated from their previous direction by an angle $(\phi)$ taken at random from a normal distribution with a standard deviation of $6^{\circ}$ (Byers, 2001). Thus, each individual's $\alpha$ direction changed at each step according to $\alpha=\alpha+\phi$. A mating or catch encounter was determined when any of the searching sex stepped into or through an $\mathrm{EAR}_{\mathrm{c}}$ of the stationary sex or trap [line segment intersecting a circle algorithm in Figure 3 of Byers (1991)]. Individuals that otherwise would leave the simulation area were made to take one or more new directions at random until they remained in the area. The two models were programmed in Java 6 (Oracle, Redwood Shores, CA, USA) and implemented visually in a Java application on a personal computer. A Java applet was made for demonstration on the Internet in a web browser (see http://www.chemicalecology.net/java2/model2.htm). Simulation results were graphed using QuickBASIC 4.5 code (Microsoft, Redmond, WA, USA) generating PostScript files for processing by Adobe Acrobat 6.0 (Adobe Systems, San Jose, CA, USA) and ReaConverter Pro v3.5 (ReaSoft Development, Seattle, WA, USA). 

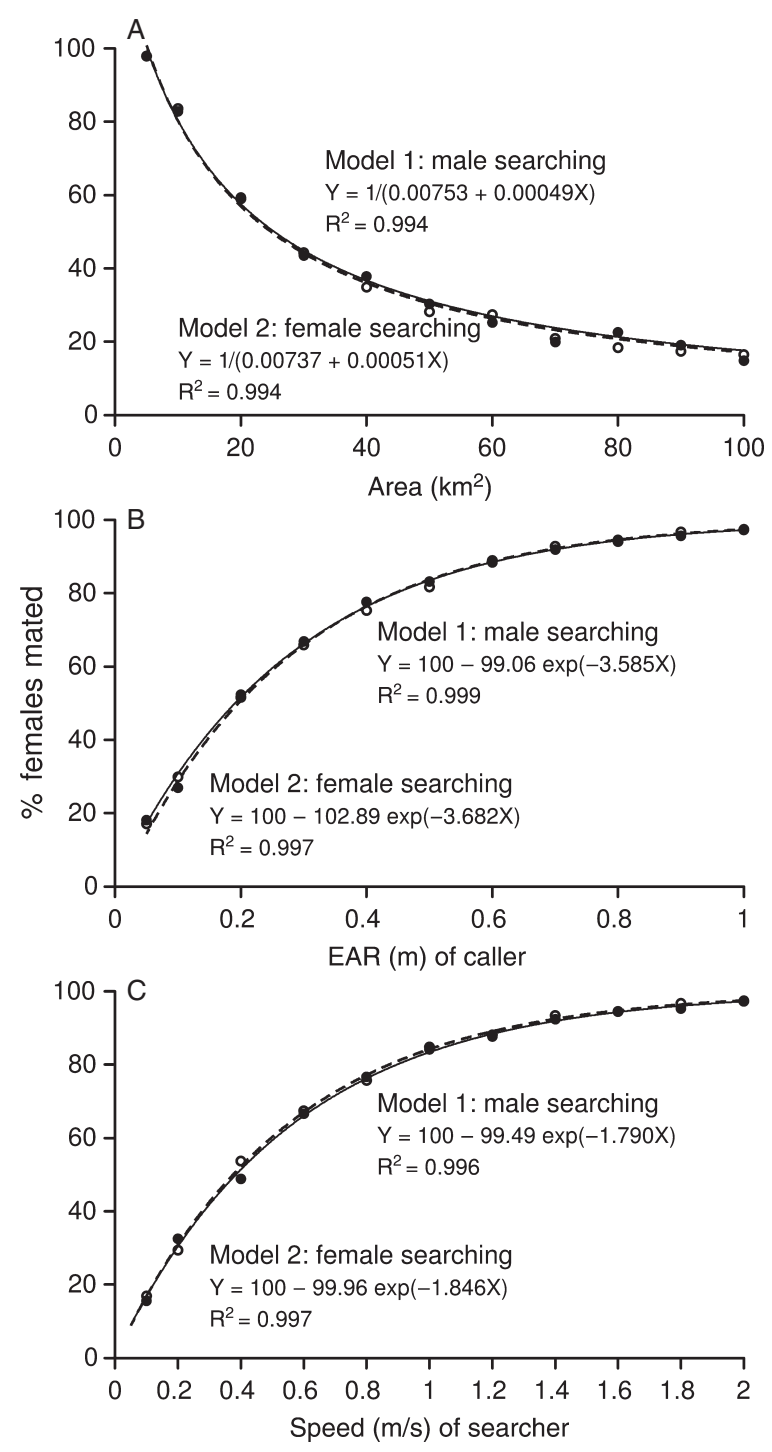

Figure 3 (A) Percentage of females mated when no traps were present in model 1 (males searching, stationary females; solid line, filled circles) or model 2 (females searching, stationary males; dashed line, open circles) depending on area. (B) Percentage of females mated when no traps were present (models as in $\mathrm{A}$ ) depending on $\mathrm{EAR}_{\mathrm{c}}$ of stationary sex.

(C) Percentage of females mated when no traps were present (models as in A) depending on flight speed of searching sex. In all cases, 1000 searching sex began to travel for up to $18 \mathrm{~km}$ (or $5 \mathrm{~h}$ ) at a speed of $1 \mathrm{~m} \mathrm{~s}^{-1}$ unless varied, in an area of $10 \mathrm{~km}^{2}$ unless varied, and 1000 stationary sex had an $\mathrm{EAR}_{\mathrm{c}}$ of $0.5 \mathrm{~m}$ unless varied.

Simulations were performed in specified areas with an initial number of stationary sex and searching sex placed in the male-searching (model 1) and female-searching (model 2) systems. To determine whether or not there were differences in the percentage of females mating during $5 \mathrm{~h}$ of searching (up to 18000 steps) in natural environments (no mass trapping), both models were compared without traps in which either area $\left(5-100 \mathrm{~km}^{2}\right)$, EAR $_{c}(0.05-1 \mathrm{~m})$, or speed $\left(0.1-2 \mathrm{~m} \mathrm{~s}^{-1}\right)$ was varied, while other parameters were kept constant (see figures and captions for specific simulation parameters). As in all simulations, females that encountered a male were mated and removed from further consideration. Mobile males continued to search after mating (male searching) and stationary males continued to call after mating (female searching). In subsequent simulations, traps were added to the models, and the hours of searching flight were varied from 0.25 to 1.75 , with initially 1000 of each sex (stationary sex $\mathrm{EAR}_{\mathrm{c}}=0.5 \mathrm{~m}$ ). The percentages of females and males that had mated within each 30 min period over the first $2 \mathrm{~h}$ were compared in the two models in which the searching sex could fly up to $10 \mathrm{~h}$ in a $1-\mathrm{km}^{2}$ area with 100 pheromone traps (each $2 \mathrm{~m} \mathrm{EAR}_{\mathrm{c}}$ ). In addition, the average distance traveled by the searching sex was calculated during the 10-h simulations.

In additional simulations, the $\mathrm{EAR}_{\mathrm{c}}$ of pheromone traps in both models was varied from 0.25 to $5 \mathrm{~m}(\mathrm{n}=8$ simulations for each value) to determine the effect of $\mathrm{EAR}_{\mathrm{c}}$ size on female mating success. Each simulation had initially 100 of each sex (calling sex $\mathrm{EAR}_{\mathrm{c}}=0.5 \mathrm{~m}$ ) and 100 traps in a 9-ha area $(300 \times 300 \mathrm{~m})$. The searching sex flew at $1 \mathrm{~m} \mathrm{~s}^{-1}$ for up to $5 \mathrm{~h}$. Similarly, the $\mathrm{EAR}_{\mathrm{c}}$ of stationary callers was varied from 0.1 to $2 \mathrm{~m}$ in both types of models that had trap $\mathrm{EAR}_{\mathrm{c}}$ of $2 \mathrm{~m}$. The initial number of each sex in a 9-ha area was varied from 20 to 450 in both models in which the calling sex had an $\mathrm{EAR}_{\mathrm{c}}$ of $0.5 \mathrm{~m}$ and there were 100 traps of 2-m EAR ${ }_{c}$. As mentioned above, the searching sex flew at $1 \mathrm{~m} \mathrm{~s}^{-1}$ for up to $5 \mathrm{~h}$ (eight simulations per value) and the percentage of the females mated was calculated. Similarly, the number of traps was varied from 10 to 300 (trap $\mathrm{EAR}_{\mathrm{c}}$ of $2 \mathrm{~m}$ ) to determine the effect of trap number on the percentage of females mating. The percentages of 1000 of each sex in each model that were still searching, had been caught, or had mated by the end of the $5 \mathrm{~h}$ simulation (up to $18 \mathrm{~km}$ search distance) in increasingly larger areas $\left(5-100 \mathrm{~km}^{2}\right)$ were determined and graphed. The percentages of females mating in the two models were compared in a two-dimensional simulation array by varying the initial number of each sex (from 50 to 500 ) and the number of pheromone traps (from 10 to 100 of $4 \mathrm{~m} \mathrm{EAR}$ ) in a $100 \times 100 \mathrm{~m}$ area. Female mating success in the female-searching model ( 1000 females in a $4-\mathrm{km}^{2}$ area) was compared between a case with 1000 males (each of $\mathrm{EAR}_{\mathrm{c}}=0.25 \mathrm{~m}$ ) to a case with male lek formation comprising 100 leks (each lek with 10 males and a larger $\mathrm{EAR}_{\mathrm{c}}=2.5 \mathrm{~m}$ proportional to lek size). 
Means of the simulations were determined as well as in many cases the $95 \%$ confidence limits of the means. Best fitting regression equations of female mating success as a function of various simulation variables were analyzed using TableCurve 2D v5.01 (Systat Software, Chicago, IL, USA).

\section{Results}

Varying the area from 5 to $100 \mathrm{~km}^{2}$ with an initial 1000 of each sex when no traps were present caused the percentage of females mating to decline from 98 to about 15\% in both the male- and the female-searching model (Figure 3A). The same parameters were used in the two models except that females and males had opposite roles of calling and searching. The curves of mating decline were not significantly different between the models and best fit a reciprocal model $\left[\mathrm{Y}=1 /(\mathrm{a}+\mathrm{bX}), \mathrm{R}^{2}>0.99\right]$ that should represent the natural mate-finding situation without mass trapping (Figure 3A). More simulations without traps showed that an increase in the $\mathrm{EAR}_{\mathrm{c}}$ of the stationary sex had decreasing benefits with regard to mating success in both models (Figure 3B). Similarly, increases in speed of the searching sex had diminishing benefits on mating success in both models (Figure 3C). These logarithmiclike increases in mating success due to increases in $\mathrm{EAR}_{c}$ or speed best fit the function $\mathrm{Y}=100-\mathrm{ae} \mathrm{e}^{\mathrm{bX}}\left(\mathrm{R}^{2}>0.99\right)$ (Figure 3). Therefore, the male- and female-searching models are identical in mating success of females when traps are not present. However, when traps are present, there are differences (Figure 4).

In the male-searching model with initially 1000 males (Figure $4 \mathrm{~A})$, the average ( $\pm 95 \%$ confidence limits) distance a male traveled was $2367 \pm 149 \mathrm{~m}$, which was also the distance before capture as all males were caught by the 100 traps before the $10 \mathrm{~h}$ period expired. Of the females, 703 mated before all males were captured, leaving 297 females unmated. The percentage of females mating and males captured was summarized every 30 min until males were nearly all caught and showed that female mating percentages were consistently lower than percentages of searching males captured (Figure 4A). This is in contrast to the female-searching model (Figure 4B) in which the percentage of females mating was higher than the percentage of searching females captured. Also, the rate of decline in mating and capture of the searching sex is less in the male-searching model than that in the female-searching model (Figure 4A and B). In the female-searching model with initially 1000 females (Figure 4B), the average distance a female traveled was $700 \pm 84 \mathrm{~m}$, whereas one female was never mated or captured in the $10 \mathrm{~h}$ period. The number of females eventually mating was 697 (nearly

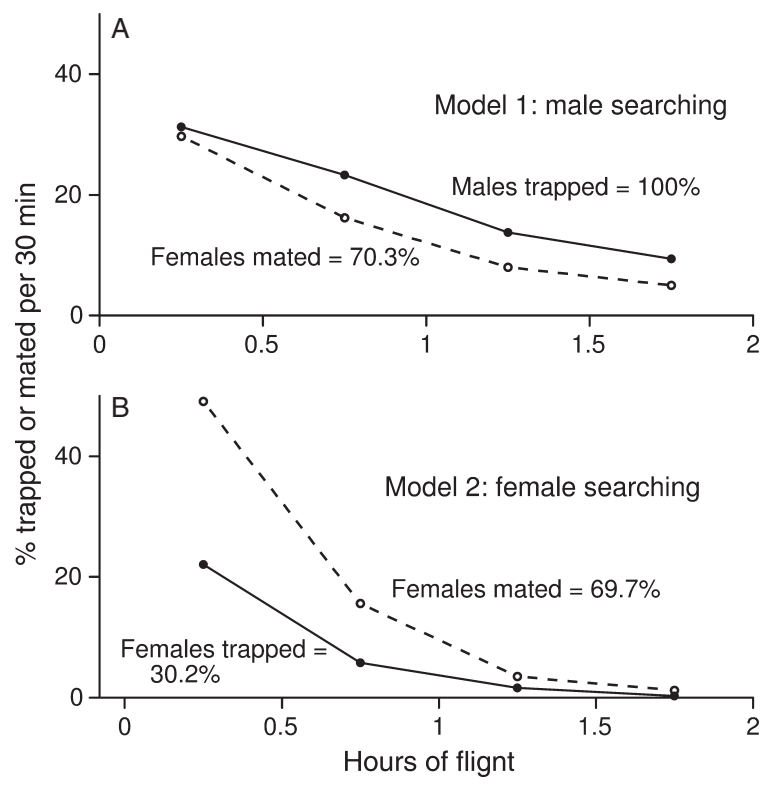

Figure 4 (A) Percentage of initial 1000 male-searching insects (solid line) caught by 100 traps $\left(\mathrm{EAR}_{\mathrm{c}}=2 \mathrm{~m}\right)$ and percentage of initial 1000 stationary females $\left(\mathrm{EAR}_{\mathrm{c}}=0.5 \mathrm{~m}\right)$ mating per 30 min period during the first $2 \mathrm{~h}$ of $10-\mathrm{h}$ maximum search time. Males flew at $1 \mathrm{~m} \mathrm{~s}^{-1}$ and any encounters with a female caused her to be removed and counted as 'mated' (dashed line), whereas males continued to search in $1000 \times 1000 \mathrm{~m}$ area, unless caught by a trap. (B) Percentage of female-searching insects (solid line) caught by traps in competition with stationary males (parameters as above) and percentage of females mating per 30min period during the first $2 \mathrm{~h}$ of 10 -h maximum search time. Females (B) flew as males (A), but any encounters with males caused the females to be removed and counted as 'mated' (dashed line). Percentages after equal signs are the total percentage mated or trapped during the 10 -h search.

identical to 703 above), whereas 302 females were captured before mating (Figure 4B). This clearly shows that there are differences in mating rates between the two models when traps are present.

If pheromone traps are competing under the model parameters above, and the searching sex travels less distance $(<1800 \mathrm{~m})$, then more females mate in the female-searching model. The percentage of females mating declined in a reciprocal function $[\mathrm{Y}=1 /(\mathrm{a}+\mathrm{bX})]$ as the size of the trap's $\mathrm{EAR}_{\mathrm{c}}$ was increased (Figure $5 \mathrm{~A}$ ). Both models were similar, but the female-searching model had slightly less mating, especially at the smaller $\mathrm{EAR}_{\mathrm{c}}$ of traps that were more comparable in size to the calling sex's EAR $_{c}$ of $0.5 \mathrm{~m}$. The percentage of females mating increased in a reciprocal hyperbolic function $[\mathrm{Y}=1 /(\mathrm{a}+\mathrm{b} / \mathrm{X})]$ as the $\mathrm{EAR}_{\mathrm{c}}$ of callers was increased (Figure $5 \mathrm{~B}$ ). The mating was similar in both models at smaller $\mathrm{EAR}_{\mathrm{c}}$ of callers, but diverged with less mating in the female-searching model at 

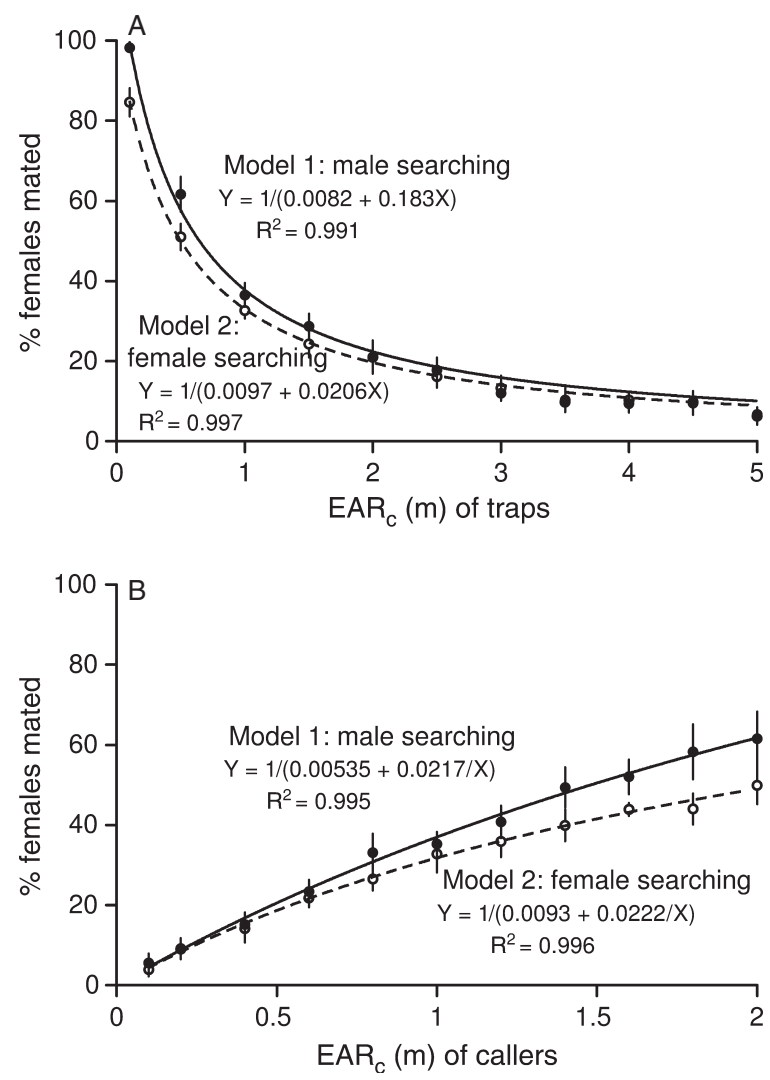

Figure 5 (A) Percentage of females mating in relation to varying trap $\mathrm{EAR}_{\mathrm{c}}$ with 100 traps in a 9-ha area (initial number of each sex was 100 and $\mathrm{EAR}_{\mathrm{c}}$ of calling sex was $0.5 \mathrm{~m}$; responders flew at $1 \mathrm{~m} \mathrm{~s}^{-1}$ for up to $5 \mathrm{~h}$; mating removed females). (B) Percentage of females mating in relation to $\mathrm{EAR}_{\mathrm{c}}$ of females (model 1) or males (model 2) (same parameters, but $\mathrm{EAR}_{\mathrm{c}}$ of trap was $2 \mathrm{~m}$ ). Means are based on $\mathrm{n}=8$ simulations, error bars represent $95 \%$ confidence limits.

larger $\mathrm{EAR}_{\mathrm{c}}$ of callers (Figure $5 \mathrm{~B}$ ). In the male-searching model, all males were caught by traps before the 5 -h search duration ended. The females not mated in the femalesearching model were all caught.

The percentage of females mating increased in a reciprocal hyperbolic relationship as the number of males or females increased from 20 to 450 in the 9-ha area in both models (Figure 6A). The female-searching model had less mating than the male-searching model when there were more females and males initially. When the initial number of males and females was held constant at 100 each and the number of traps was increased from 10 to 300, the percentage of females mating declined as a reciprocal relationship (Figure 6B). The mating was somewhat less in the femalesearching model compared to the male-searching model when the density of traps was lower (Figure 6B). In all cases, searching males, and those searching females that


Figure 6 (A) Percentage of females mating in relation to initial number of females (model 1) or males (model 2) with $\mathrm{EAR}_{\mathrm{c}}$ of $0.5 \mathrm{~m}$ and 100 traps of $2 \mathrm{~m} \mathrm{EAR}_{\mathrm{c}}$ in a 9-ha area (equal number of each sex initially; responders flew at $1 \mathrm{~m} \mathrm{~s}^{-1}$ for up to $5 \mathrm{~h}$; mating removed females). (B) Percentage of females mating in relation to the number of traps (same parameters but initial number of each sex was 100). Means are based on $n=8$ simulations, error bars represent $95 \%$ confidence limits.

had not mated, were all caught before the simulations finished. The percentages of the males still searching at the end of $5 \mathrm{~h}$ in the male-searching model increased as the area was increased from 5 to $100 \mathrm{~km}^{2}$, whereas the mutually exclusive event of male catch was inversely related (Figure 7). The number of females mated in the malesearching model declined with larger area and was very similar to females mated in the female-searching model. The number of females caught was less than the number of males caught at higher densities, but became nearly the same at lower densities (Figure 7). The number of females searching appears to exhibit a sigmoid increase as area is increased in the female-searching model. These numbers of females were considerably lower than the numbers of males searching in the same area in the male-searching model. Varying two parameters, initial number of each sex from 50 to 500 and number of traps from 10 to 100 , showed that the percentage of females mating was similar, but slightly more in the male-searching model (Figure 8A) than that in the female-searching model (Figure 8B). The 




Figure 7 Percentage of 1000 of each sex that were either searching, caught, or mated (females) at the end of a 5-h period in model 1 (male search, solid lines) or model 2 (female search, dashed lines) depending on area. Simulations had 100 traps of $2 \mathrm{~m} \mathrm{EAR}_{\mathrm{c}}$, stationary sex had $0.5 \mathrm{~m} \mathrm{EAR}_{\mathrm{c}}$, searching sex parameters as in Figure $6\left[1 \mathrm{~m} \mathrm{~s}^{-1}, 6 \mathrm{SDA}\right.$, best fitting regressions as $\mathrm{Y}=1 /(\mathrm{a}+\mathrm{bx})$ or $\mathrm{Y}=1 /(\mathrm{a}+\mathrm{b} / \mathrm{x})]$.

lowest initial densities of males and females and the highest densities of traps allowed the least number of females to mate in both models.

The female-searching model in a $4-\mathrm{km}^{2}$ area where initially 1000 females searched at $1 \mathrm{~m} \mathrm{~s}^{-1}$ up to $5 \mathrm{~h}$ for 1000 males calling individually $\left(\mathrm{EAR}_{\mathrm{c}}=0.25 \mathrm{~m}\right)$ resulted in $89.2 \pm 1.6 \%$ of the females mating. This was nearly identical to $88.2 \pm 1.5 \%$ females mating in the same model in which males formed 100 leks (10 males per lek) with a proportionately larger lek $\mathrm{EAR}_{\mathrm{c}}$ of $2.5 \mathrm{~m}$.

\section{Discussion}

There was no difference in mating frequency between the male-searching model (model 1) and the female-searching model (model 2) under natural conditions without the presence of pheromone traps (Figure 3). The models suggest that there should be a cost-benefit limitation to evolving larger $\mathrm{EAR}_{\mathrm{c}}$ by producing more pheromone because a linear increase in $\mathrm{EAR}_{\mathrm{c}}$ resulted in diminishing increases with regard to mating success (Figure 3B). Similarly, insects should have cost limitations to evolving increasingly faster flight speeds that would result in successively smaller increases in mating success (Figure 3C). An additional constraint on evolving ever larger $\mathrm{EAR}_{\mathrm{c}}$ is that linear increases in $\mathrm{EAR}_{\mathrm{c}}$ require exponential increases in pheromone release rate (Byers, 1988; Byers et al., 1988). When there is competitive attraction by traps, the malesearching model (model 1) limits the mating of females at any point in time due to the number of remaining males not caught by traps. In the female-searching model (model 2 ), the mating of females is limited by the possibility of
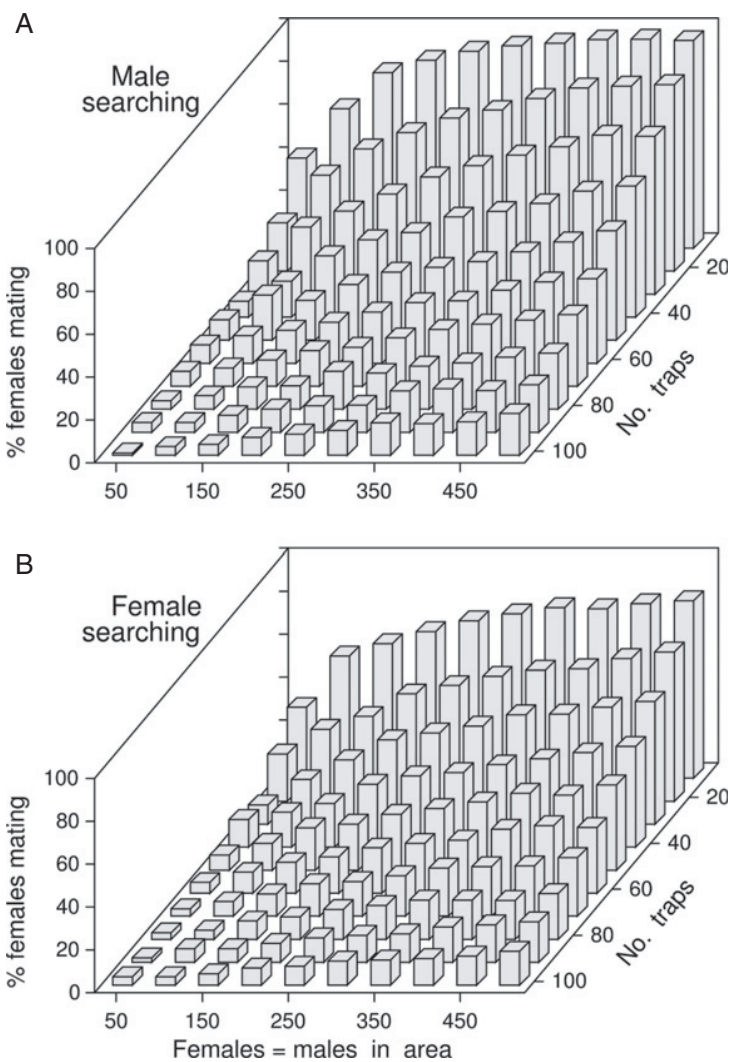

Figure 8 (A) Percentage of females mating in the male-searching model depending on the initial number of each sex and number of traps. (B) Percentage of females mating in the femalesearching model depending on the initial number of each sex and number of traps. In both models, the searching sex moves for up to $5 \mathrm{~h}$ in a 1-ha area, the calling sex has $\mathrm{EAR}_{\mathrm{c}}$ of $0.5 \mathrm{~m}$ and traps have $\mathrm{EAR}_{\mathrm{c}}$ of $4 \mathrm{~m}$ (bars are means of $\mathrm{n}=4$ simulations). [Correction added after online publication 15 October 2012: figure replaced as, in the original version, the last rows of bar data in both $\mathrm{A}$ and $\mathrm{B}$ were not shown and the first two rows of data bars in A and B were identical]

being lured into a trap before encountering a male. In model 2 , the proportion of females mating would be lower than in model 1, because the females can be caught in traps before finding a male, whereas in model 1 a higher proportion of females would mate as none are ever trapped. However, because males in model 2 are never trapped, whereas males in model 1 are, does this compensate the females in both models so that they mate at about the same proportions?

It is not immediately obvious which model system is most affected by mass trapping. With traps present, the time progression of mated females is different with about $30 \%$ of females mating in the first 30 min in model 1 compared to $50 \%$ in model 2; although after several hours of searching, the total percentage of females mated is nearly 
identical at $70 \%$ in both models (Figure 4). Also, none of the females are trapped (whereas all males are) in model 1 compared to $30 \%$ of females trapped and no males trapped in model 2. The percentages of females mated at different $\mathrm{EAR}_{\mathrm{c}}$ of traps followed the same relationships in the two models. However, at smaller $\mathrm{EAR}_{\mathrm{c}}$ of traps, the mating percentages ranged up to $15 \%$ higher in the male-searching model, because smaller $\mathrm{EAR}_{\mathrm{c}}$ were less effective in earlier removal of the searching sex than larger $\mathrm{EAR}_{\mathrm{c}}$ (Figure $5 \mathrm{~A}$ ). The percentages of females mated at different $\mathrm{EAR}_{\mathrm{c}}$ of the calling sex were also similar in the two models, but ranged up to $15 \%$ higher in the male-searching model at larger female $E A R_{c}$, because traps did not remove females, whereas this was possible in the second model (Figure 5B). This same effect of stationary females in model 1 caused a larger percentage of females to mate at higher densities of insects (Figure 6A) as well as at lower densities of traps (Figure 6B). These effects of varying trap and insect density in two-dimensional simulations show that the femalesearching model allows somewhat fewer females to mate, and as expected, lower densities of insects and higher densities of traps cause the least female mating (Figure 8A and B). Thus, insects that exhibit a female-searching system would be controlled slightly more effectively than those in a male-searching system (as in moth control programs). Both models allowed each female to mate no more than once, but even if females were allowed to mate multiple times the percentage of females mating would not change (a female who mates multiple times is still mated). In model 2 with traps, if females continue searching for multiple mates then they can be caught before laying eggs, which would select for females mating once.

A lek is defined as two or more males that aggregate in a specific location for the sole purpose of mating (Field et al., 2002). Lek evolution has been explained by presuming that in leks the males either have a lower per capita predation rate or a higher per capita mating rate, or both (Hoglund \& Alatalo, 1995). Higher mating rates have been found in experiments with large numbers of caged males of the Mediterranean fruit fly, but not in oriental fruit fly (Shelly, 2001). Is evolution of lek formation favored by $\mathrm{EAR}_{\mathrm{c}}$ curves of dose-response tests in the field? Leks with more males could attract relatively more females depending on the size increase of the $\mathrm{EAR}_{\mathrm{c}}$ in relation to pheromone release rate. However, assuming a linear increase in $\mathrm{EAR}_{\mathrm{c}}$ with a linear increase in pheromone release rate (or number of males), there should be no effect on the number of females mating per male. This was confirmed in simulations when the same female mating occurred when individual males called $\left(0.25 \mathrm{~m} \mathrm{EAR}_{\mathrm{c}}\right)$ or when they formed leks of 10 males with proportionately larger $\mathrm{EAR}_{\mathrm{c}}$ of $2.5 \mathrm{~m}$. Only if there were an exponential (synergistic) increase in
$\mathrm{EAR}_{\mathrm{c}}$ with a linear increase in pheromone release (male number) would it be expected that males would gain proportionately more mating in a lek than would a single calling male. Although dose-response tests in the field with fruit flies are lacking, the catch of the bark beetle Pityogenes chalcographus (L.) increased in a logarithmic relationship with male pheromone release rate [ catch $=1802+457.5$. $\log$ (dose), where dose $=0.1,1$, or $10, \mathrm{R}^{2}=0.98$; Table 1 in Byers et al., 1988; test 4]. Similarly, Dendroctonus brevicomis Le Conte catch was related logarithmically with dosage $[$ catch $=332+45 \cdot \log ($ dose $)$, where dose $=0.01$, 0.1 , or $1, \mathrm{R}^{2}>0.99$; Table 1 in Byers, 1988]. If $\mathrm{EAR}_{\mathrm{c}}$ of attractive pheromones increases in a logarithmic relationship with release rate, then we should not expect leks to evolve, because larger leks (e.g., 20 males) would not have proportionately larger $\mathrm{EAR}_{\mathrm{c}}$ compared to the sum of 20 single males of smaller $\mathrm{EAR}_{\mathrm{c}}$. So is there another reason why males form leks?

Leks of fruit flies appear more often to form on certain fruit tree species, larger trees and nearby trees (Shelly \& Whittier, 1993), or on fruit (Kaspi \& Yuval, 1999; Quilici et al., 2002), or in sunlit areas in the morning (Segura et al., 2007). Thus, considering these reports and that $\mathrm{EAR}_{\mathrm{c}}$ appears logarithmically related to male numbers, it is more likely that males of some species evolved leks because of the 'hotspots' theory (Field et al., 2002), which is supported by the models here. Hotspots are places in the habitat where females are concentrated or pass through, and if males form leks in these areas then they can attain a higher frequency of mating (Hoglund \& Alatalo, 1995; Field et al., 2002). The simulations show that relatively more mating occurs when a constant number of insects are placed in an increasingly smaller area (Figures $3 \mathrm{~A}$ and 7 ) or when increasingly higher numbers are in a constant area (Figures 6A and 8), showing that higher densities of insects cause higher percentages of mating. Thus, males and females that congregate in a limited area of the habitat, such as on host plants can increase their density and mating frequency. Males that did not join a lek would likely be in low-density areas and not encounter as many females. Females may have little choice but to seek the highest densities of males (a lek), but the females could also gain even more fitness if they are able to choose higher quality males in the group, or if the males are territorial and only the best males can stay inside the lek (Hoglund \& Alatalo, 1995; Field et al., 2002). Furthermore, as males are the calling sex in fruit flies, it is more likely that any such female choice and male territoriality evolved after male leks evolved. Females do not form leks because additional mating after fertilization of eggs yields little or no benefit and would delay searching for suitable oviposition sites (Jarvis \& Rutledge, 1992; Cabrera \& Jaffe, 2007). 
The models here have pheromone traps that compete with natural pheromone (competitive attraction), but also have a possible second mechanism of camouflaging the stationary sex. Camouflage occurs if a caller's $\mathrm{EAR}_{\mathrm{c}}$ circle is partially or completely within a trap's $\mathrm{EAR}_{\mathrm{c}}$ circle, which reduces or prevents encounters by the searching sex (Figure 2). The female-searching model can accommodate leks by making fewer and larger $\mathrm{EAR}_{\mathrm{c}}$ for the male groups. For example, 100 males were partitioned into 10 leks of 10 males each. However, the size of the $\mathrm{EAR}_{\mathrm{c}}$ would be difficult to estimate and in nature the mating groups would be expected to be of all sizes from a single male to leks up to tens of males (Shelly, 2001; Field et al., 2002). Dose-response tests in the field are needed for fruit flies along with EAR measurements before meaningful models can be attempted. In any case, a lek model of male searching is not easily compared to the male-searching model of moths, whereas sex pheromones of single males are straightforward to compare.

Mass trapping with competitive attraction by natural pheromone is always more efficient than mating disruption when both have an equal number of pheromone sources of the same $\mathrm{EAR}_{\mathrm{c}}$. This is because mating disruption only delays the searching sex, whereas a trap delays them indefinitely (Byers, 2007). However, the $\mathrm{EAR}_{\mathrm{c}}$ in many species cannot be made as large as desired by increasing pheromone release rates. This is because (1) logarithmic dosage curves indicate that amounts needed for a linear increase in catch or $\mathrm{EAR}_{\mathrm{c}}$ require exponential increases in release rate, which is increasingly expensive (Byers, 2007); (2) based on models here (Figure 3), a linear increase in $\mathrm{EAR}_{\mathrm{c}}$ results in a logarithmic-like increase in mate finding; and (3) many insects are inhibited by a high release rate such that the $\mathrm{EAR}_{\mathrm{c}}$ can even become smaller (e.g., male moths; Roelofs \& Cardé, 1977). Therefore, mating disruption can be more cost-effective than mass trapping because many more sources of pheromone can be employed at a sufficiently large $\mathrm{EAR}_{\mathrm{c}}$ without the need of relatively higher expenses of traps and their deployment. The models show that insects with sex pheromones with either female- or male-searching behavior are equally efficient in finding mates in natural systems. However, with mass trapping (or mating disruption) the female-searching system has somewhat less mating than the male-searching system.

\section{References}

Borges M, Millar JG, Laumann RA \& Moraes CB (2007) A maleproduced sex pheromone from the neotropical redbanded stink bug, Piezodorus guildinii (W.). Journal of Chemical Ecology 33: 1235-1248.
Brézot P, Malosse C, Mori K \& Renou M (1994) Bisabolene epoxides in sex pheromone in Nezara viridula (L.) (Heteroptera: Pentatomidae) role of cis isomer and relation to specificity of pheromone. Journal of Chemical Ecology 20: 31333147.

Byers JA (1988) Novel diffusion-dilution method for release of semiochemicals: testing pheromone component ratios on western pine beetle. Journal of Chemical Ecology 14: 199-212.

Byers JA (1991) Simulation of mate-finding behaviour of pine shoot beetles, Tomicus piniperda. Animal Behaviour 41: 649-660.

Byers JA (2001) Correlated random walk equations of animal dispersal resolved by simulation. Ecology 82: 1680-1690.

Byers JA (2006) Pheromone component patterns of moth evolution revealed by computer analysis of the Pherolist. Journal of Animal Ecology 75: 399-407.

Byers JA (2007) Simulation of mating disruption and mass trapping with competitive attraction and camouflage. Environmental Entomology 36: 1328-1338.

Byers JA (2008) Active space of pheromone plume and its relationship to effective attraction radius in applied models. Journal of Chemical Ecology 34: 1134-1145.

Byers JA (2009) Modeling distributions of flying insects: effective attraction radius of pheromone in two and three dimensions. Journal of Theoretical Biology 256: 81-89.

Byers JA (2011) Analysis of vertical distributions and effective flight layers of insects: three-dimensional simulation of flying insects and catch at trap heights. Environmental Entomology 40: $1210-1222$.

Byers JA (2012) Estimating insect flight densities from attractive trap catches and flight height distributions. Journal of Chemical Ecology 38: 592-601.

Byers JA, Birgersson G, Löfqvist J \& Bergström G (1988) Synergistic pheromones and monoterpenes enable aggregation and host recognition by a bark beetle, Pityogenes chalcographus. Naturwissenschaften 75: 153-155.

Byers JA, Anderbrant O \& Löfqvist J (1989) Effective attraction radius: a method for comparing species attractants and determining densities of flying insects. Journal of Chemical Ecology 15: 749-765.

Cabrera M \& Jaffe K (2007) An aggregation pheromone modulates lekking behavior in the vector mosquito Aedes aegypti (Diptera: Culidicae). Journal of the American Mosquito Control Association 23: 1-10.

Cardé RT (1990) Principles of mating disruption. BehaviorModifying Chemicals for Pest Management: Applications of Pheromones and other Attractants (ed. by RL Ridgway \& RM Silverstein), pp. 47-71. Marcel Dekker, New York, NY, USA.

Cardé RT \& Minks AK (1995) Control of moth pests by mating disruption: successes and constraints. Annual Review of Entomology 40: 559-585.

Chuman T, Landolt PJ, Heath RR \& Tumlinson JH (1987) Isolation, identification, and synthesis of male-produced sex pheromone of papaya fruit fly, Toxotrypana curvicauda Gerstaecker (Diptera: Tephritidae). Journal of Chemical Ecology 13: 19791992. 
Cooperband MF, Böröczky K, Hartness A, Jones TH, Zylstra KE et al. (2012) Male-produced pheromone in the European woodwasp, Sirex noctilio. Journal of Chemical Ecology 38: 52-62.

El-Sayed AM, Suckling DM, Wearing CH \& Byers JA (2006) Potential of mass trapping for long-term pest management and eradication of invasive species. Journal of Economic Entomology 99: 1550-1564.

El-Sayed AM, Suckling DM, Byers JA, Jang EB \& Wearing CH (2009) Potential of 'lure and kill' in long-term pest management and eradication of invasive species. Journal of Economic Entomology 102: 815-835.

Farine J-P, Le Quere JL, Duffy J, Everaerts C \& Brossut R (1994) Male sex pheromone of cockroach Eurycotis floridana (Walker) (Blattidae, Polyzosteriinae): role and composition of tergites 2 and 8 secretions. Journal of Chemical Ecology 20: 22912306.

Farine J-P, Sirugue D, Abed-Vieillard D, Everaerts C, Le Quéré J-L et al. (2007) The male abdominal glands of Leucophaea maderae: chemical identification of the volatile secretion and sex pheromone function. Journal of Chemical Ecology 33: 405-415.

Field SA, Kaspi R \& Yuval B (2002) Why do calling medflies (Diptera: Tephritidae) cluster? Assessing the empirical evidence for models of medfly lek evolution. Florida Entomologist 85: 63-72.

Geiselhardt S, Jakobschy D, Ockenfels P \& Peschke K (2008) A sex pheromone in the desert tenebrionid beetle Parastizopus armaticeps. Journal of Chemical Ecology 34: 1065-1071.

Hall DR, Cork A, Phythian SJ, Chittamuru S, Jayarama BK et al. (2006) Identification of components of male-produced pheromone of coffee white stemborer, Xylotrechus quadripes. Journal of Chemical Ecology 32: 195-219.

Halstead DGH (1973) Preliminary biological studies on the pheromone produced by male Acanthoscelides obtectus (Say) (Coleoptera: Bruchidae). Journal of Stored Product Research 9: 109-117.

Hamilton JGC, Dawson GW \& Picket JA (1996) 3-Methyl- $\alpha$-himachalene: proposed structure for novel homosesquiterpene sex pheromone of Lutzomyia longipalpis (Diptera: Psychodidae) from Jacobina, Brazil. Journal of Chemical Ecology 22: 2331-2340.

Hoglund U \& Alatalo RV (1995) Leks. Princeton University Press, Princeton, NJ, USA.

Jacobson M, Ohinata K, Chambers DL, Jones WA \& Fujimoto MS (1973) Insect sex attractants. 13. Isolation, identification, and synthesis of sex pheromones of the male Mediterranean fruit fly. Journal of Medicinal Chemistry 16: 248-251.

Jarvis EK \& Rutledge LC (1992) Laboratory observations on mating and leklike aggregations in Lutzomyia longipalpis (Diptera: Psychodidae). Journal of Medical Entomology 29: 171-177.

Kaspi R \& Yuval B (1999) Lek site selection by male Mediterranean fruit flies. Journal of Insect Behavior 12: 267-276.

Khoo CC-H, Yuen K-H \& Tan K-H (2000) Attraction of female Bactrocera papayae to sex pheromone components with two different release devices. Journal of Chemical Ecology 26: 2487-2496.
McBrien HL, Millar JG, Gottlieb L, Chen X \& Rice RE (2001) Male-produced sex attractant pheromone of the green stink bug, Acrosternum hilare (Say). Journal of Chemical Ecology 27: 1821-1839.

McBrien HL, Millar JG, Rice RE, McElfresh JS, Cullen E \& Zalom FG (2002) Sex attractant pheromone of the red-shouldered stink bug Thyanta pallidovirens: a pheromone blend with multiple redundant components. Journal of Chemical Ecology 28: 1797-1817.

Miller JR, Gut LJ, De Lame FM \& Stelinski LL (2006a) Differentiation of competitive vs. non-competitive mechanisms mediating disruption of moth sexual communication by point sources of sex pheromone (Part 1): theory. Journal of Chemical Ecology 32: 2089-2114.

Miller JR, Gut LJ, De Lame FM \& Stelinski LL (2006b) Differentiation of competitive vs. non-competitive mechanisms mediating disruption of moth sexual communication by point sources of sex pheromone (Part 2): case studies. Journal of Chemical Ecology 32: 2115-2143.

Quilici S, Franck A, Peppuy A, Dos Res Correia E, Mouniama C \& Cirad-Flhor FB (2002) Comparative studies of courtship behavior of Ceratitis spp. (Diptera: Tephritidae) in Reunion Island. Florida Entomologist 85: 138-142.

Robacker DC (1988) Behavioral responses of female Mexican fruit flies, Anastrepha ludens, to components of male-produced sex pheromone. Journal of Chemical Ecology 14: 1715-1726.

Robacker DC, Aluja M, Cossé AA \& Sacchetti P (2009) Sex pheromone investigation of Anastrepha serpentina (Diptera: Tephritidae). Annals of the Entomological Society of America 102: 560-566.

Roelofs WL \& Cardé RT (1977) Responses of Lepidoptera to synthetic sex pheromone chemicals and their analogues. Annual Review of Entomology 22: 377-405.

Segura D, Petit-Marty N, Sciurano R, Vera T, Calcagno G et al. (2007) Lekking behavior of Anastrepha fraterculus (Diptera: Tephritidae). Florida Entomologist 90: 154-162.

Shelly TE (2001) Lek size and female visitation in two species of tephritid fruit flies. Animal Behaviour 62: 33-40.

Shelly TE \& Whittier TS (1993) Lek distribution in the Mediterranean fruit fly (Diptera: Tephritidae): influence of tree size, foliage density, and neighborhood. Proceedings of the Hawaiian Entomological Society 32: 113-121.

Shorey HH (1977) Manipulation of insect pests of agricultural crops. Chemical Control of Insect Behaviour: Theory and Application (ed. by HH Shorey \& JJ McKelvey, Jr), pp. 353-367. Wiley, New York, NY, USA.

Sreng L (1990) Seducin, male sex pheromone of the cockroach Nauphoeta cinerea: isolation, identification, and bioassay. Journal of Chemical Ecology 16: 2899-2912.

Wicker-Thomas C (2007) Pheromonal communication involved in courtship behavior in Diptera. Journal of Insect Physiology 53: 1089-1100.

Wu H, Wu K, Wang D \& Guo Y (2006) Flight potential of pink bollworm, Pectinophora gossypiella Saunders (Lepidoptera: Gelechiidae). Environmental Entomology 35: 887-893. 